\title{
CRESCIMENTO DE RAÍZES DE CANA CRUA E QUEIMADA EM DOIS CICLOS ${ }^{1}$
}

\author{
Ivan André Alvarez ${ }^{2}$; Paulo Roberto de Camargo e Castro ${ }^{3}$ : Maria Cristina Stolf Nogueira ${ }^{4}$ \\ ${ }^{2}$ Pós-Graduando do Depto. de Ciências Biológicas - USP/ESALQ. \\ ${ }^{3}$ Depto. de Ciências Biológicas - USP/ESALQ, C.P. 9 - CEP: 13418-900 - Piracicaba, SP. \\ ${ }^{4}$ Depto. de Ciências Exatas - USP/ESALQ. \\ *Autor correspondente <iaalvare@pir.zaz.com.br>
}

RESUMO: Este trabalho teve como objetivos comparar o crescimento de raízes de cana colhida crua, mecanizada e de cana após a queima, colhida manualmente; avaliar a influência do clima sobre as duas condições de crescimento e analisar o comportamento do crescimento de raízes de cana crua e cana queimada nos $1^{\circ}$ e $2^{\circ}$ anos de rebrota, através de curvas adaptadas. A pesquisa foi realizada no município de Morro Agudo, SP, de julho de 1995 a julho de 1997. A cultivar utilizada foi a SP 70-1143. Utilizou-se como indicadores de crescimento das raízes a matéria seca e o perfil delas no solo. Avaliou-se a influência das temperaturas e das umidades do ar e do solo sobre os tratamentos. Observou-se que o crescimento, no primeiro e no segundo ciclo, não apresentou curvas que indicassem um padrão semelhante, tanto para cana crua, como para cana queimada, os fatores climatológicos, isoladamente, não provocaram mudanças nos ciclos de crescimento de maneira que se identificasse uma tendência geral. As raízes aparecem em maior quantidade em todas camadas do solo em cana crua do que em cana queimada, no primeiro ano e no segundo ano aparecem maiores em cana queimada.

Palavras-chave: cana-de-açúcar, desenvolvimento, sistema radicular, ecofisiologia

\section{ROOT GROWTH OF CANE RATTOONS HARVESTED GREEN OR BURNED}

\begin{abstract}
To compare sugarcane rattoons root growth, after mechanical harvest (green) and after manual harvest (burned) in two cicles of different climatic conditions, the sugar cane cultivar SP 70-1143 was used. As root growth indicators, dry matter and rooting profiles were analysed. The influence of air and soil temperatures, and relative humidities were also evaluated. Growth curves, in the first and in the second cycles, did not present a similar pattern, for both green and burned cane. Climatological factors did not cause changes in growth cycles. Roots appear in a greater proportion in the green cane plots in all soil layers, in the first year, as compared to the burned plots.
\end{abstract}

Key words: sugar cane, ecophysiology, development, environmental impact

\section{INTRODUÇÃO}

Em cana-de-açúcar as raízes desenvolvem-se logo em seguida ao plantio, a partir das reservas do tolete. Blackburn (1984) destaca que no início do desenvolvimento radicular, são formadas as raízes de fixação que suprirão os rebentos que brotarão das gemas.

$O$ desenvolvimento radicular foi mais estudado em cana-planta que em cana-soca, por isso existem poucas informações sobre o desenvolvimento radicular em canasoca. Segundo Sampaio et al. (1987), o sistema radicular de cana-de-açúcar merece atenção particular, porque é essencial para a regeneração das soqueiras após a colheita.

Casagrande (1991) relata que ao mesmo tempo que vai havendo a brotação das socas, um novo sistema radicular é formado e algumas raízes vivas seriam importantes para alimentar os rebentos, na fase inicial de desenvolvimento. Raízes de cana-soca estão mais sujeitas a condições mais adversas do solo causadas pelo tráfego; por isso, pelo ciclo mais curto e pela brotação do tolete dar-se próximo à superfície do solo, as raízes da soca são mais superficiais do que as da cana-planta. Quanto mais cortes forem realizados, maior a possibilidade do sistema radicular das socas localizar-se superficialmente. Por outro lado, no final do ciclo da cana-planta, as raízes mais novas são superficiais, pois ao longo do desenvolvimento radicular, as ramificações secundárias ocorrem após o crescimento em alongamento, nos nós situados mais acima do rebento.

Fernandes (1979) observou que o sistema radicular de cana-planta é mais desenvolvido que o da rebrota, diferentemente de Ball-Coelho et al. (1992) que relataram a maior quantidade de raízes na cana-soca. Contudo, Ball-Coelho et al. (1992) consideram raízes vivas e mortas, o que já não está claro em Fernandes (1979).

Korndörfer et al. (1989) encontraram maior percentual de matéria seca de raiz sobre parte aérea de cana-soca, comparado à cana-planta, talvez devido à época de amostragem, realizada aos 4,5 meses de idade, 
com grande possibilidade de haver resíduo do sistema radicular da cana-planta. Já aos 10,6 meses do plantio, num solo Latossolo Vermelho álico, encontraram-se $90 \%$ da massa radicular nos primeiros $30 \mathrm{~cm}$. A variedade $S P$ 70-1143 apresentou maior massa seca de raízes entre os 5 genótipos estudados e encontrou-se uma relação raiz / parte aérea de $10,2 \%$.

A incorporação de raiz durante o período de crescimento também pode constituir um significante acréscimo de material orgânico ao solo e determina 0 volume efetivo de solo explorado pelas raízes (Ball-Coelho et al., 1992).

Durante o desenvolvimento da cana-de-açúcar, a matéria seca radicular e da parte aérea distribuem-se em função das condições ambientais (Machado, 1987). A variação na distribuição relativa das raízes nas primeiras camadas deve-se principalmente à variação da umidade do solo, segundo Inforzato \& Alvarez (1957).

Para Sampaio et al. (1987), deve-se dar maior importância ao sistema radicular, porque é ele que serve de reserva de nutrientes para a rebrota das socas. $O$ mesmo autor ainda identificou que $75 \%$ da massa radicular estava localizada nos primeiros $20 \mathrm{~cm}$ superficiais e $55 \%$ estavam a menos de $30 \mathrm{~cm}$ do centro da touceira.

Inforzato \& Alvarez (1957) obtiveram resultados demonstrativos de que a distribuição do sistema radicular apresenta-se bem homogênea, nas camadas superficiais do solo, sendo que o maior adensamento ocorre nos primeiros 30 cm (59\%). Já Ball-Coelho et al. (1992) encontraram 62,69 $\%$ da matéria seca total de raízes nos primeiros $50 \mathrm{~cm}$ de profundidade, com 38-48\% das raízes vivas nos $30 \mathrm{~cm}$ iniciais. Esses autores mostraram também que, quando se trata de massa total de raízes, a referência é das raízes mais próximas aos colmos da touceira do que daquelas longe dos mesmos; esse padrão é mais marcante nas camadas superiores do solo, mas não existe abaixo de $1 \mathrm{~m}$.

Os objetivos desse trabalho foram comparar o crescimento de raízes de cana colhida crua, mecanizada e de cana após a queima, colhida manualmente; avaliar a influência do clima sobre as duas condições de crescimento e analisar o comportamento do crescimento de raízes de cana crua e cana queimada nos $1^{\circ}$ e $2^{\circ}$ anos de rebrota, através de curvas adaptadas.

\section{MATERIAL E MÉTODOS}

O experimento foi instalado em área da Usina Santa Elisa, Fazenda Barra do Agudo, no município de Morro Agudo, Estado de São Paulo, cuja localização do campo experimental está a 509 metros de altitude, a $20^{\circ} 48^{\prime} 36^{\prime \prime}$ latitude sul e $48^{\circ} 13^{\prime} 37^{\prime \prime}$ longitude oeste. O solo do local do experimento é classificado como Latossolo Vermelho Escuro Distrófico. A variedade utilizada foi a SP 70-1143.

A cana foi plantada em 21 de fevereiro de 1994 , em sulcos feitos a uma profundidade de $25 \mathrm{~cm}$, com um espaçamento entre linhas de $1,35 \mathrm{~m}$ e uma densidade de plantio de 14 gemas / $\mathrm{m}$.
Os dados utilizados para a análise do experimento foram coletados durante três anos. O primeiro ano da coleta de dados da cana-soca deu-se aos 37, 80, 114, 150, 213, 247, 282, 308 e 339 dias após o corte da cana-planta. O segundo ano inclui dados coletados aos $37,68,101,131$, 167, 198, 241, 272, 314 e 344 dias após o segunda corte da cana. A primeira, segunda e terceira colheitas ocorreram em 16 de julho de 1995, 24 de julho de 1996, 27 de julho de 1997, respectivamente. Os tratamentos utilizados foram dois: $1^{0}$ cana colhida crua e por meio mecanizado e $2^{\circ}$ - cana colhida queimada e manualmente. A colheita da cana crua foi feita com colhedora Santal, modelo Amazón e após a colheita, não houve retirada da palha que permaneceu espalhada sobre o solo.

Foram destinados 4 talhões com 4 linhas de 20 metros de extensão cada uma, para cada tratamento, sendo esses dispostos alternadamente para cada tratamento no campo. O talhão foi considerado como repetição.

A massa do material seco amostrado das raízes foi obtida através de adaptação do método de Kopke (1981). Após o corte da parte aérea dC a planta, retiraramse amostras das raízes, juntamente com terra, através da utilização de trado manual tradicional (volume $4,19 \mathrm{~cm}^{3}$ ), sem que fosse preciso abrir trincheiras no solo. A amostragem do perfil de raízes das touceiras de cana, constituída de 25 subamostras (volume total $104,72 \mathrm{~cm}^{3}$ ), foi definida num perfil de solo perpendicular à cultura, com o eixo da planta na posição central. As subamostras, consideradas cada uma como um volume do trado, foram distribuídas como mostra a Figura 1.

Em seguida, as porções de solo e raiz das subamostras, obtidas pelo trado, foram separadas em peneira de malha grossa. $\mathrm{O}$ solo foi descartado, enquanto que as amostras de raízes levadas ao laboratório foram lavadas com água, para retirada total do solo aderido, e submetidas à secagem em estufa a $70^{\circ} \mathrm{C}$, por três dias.

A quantificação radicular foi efetuada, utilizandose a massa de material seco de raiz obtida em pesagem com balança de precisão de 3 casas $P 1200 N$, com resultados expressos em grama por metro quadrado.

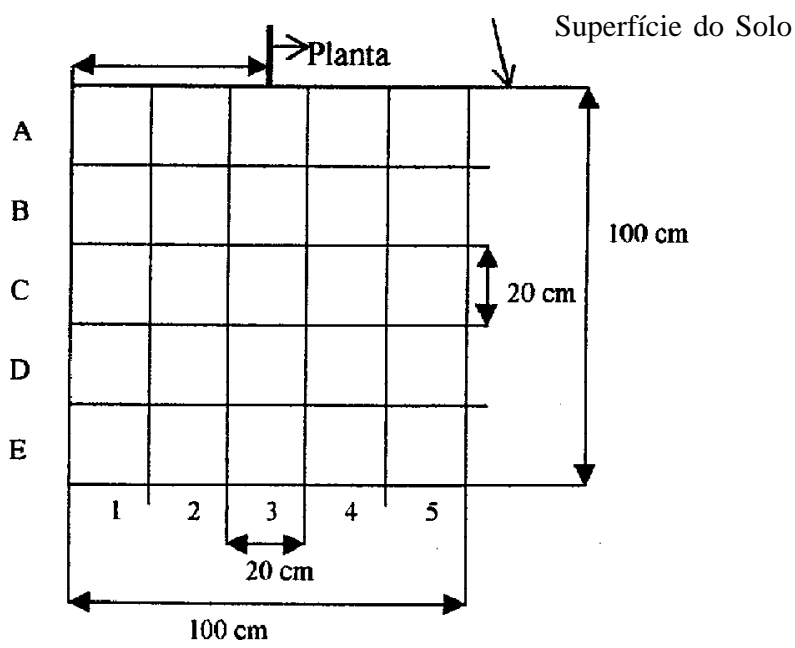

Figura 1 - Desenho esquemático das regiões amostradas para a avaliação radicular. 
Para se quantificar a influência do clima sobre o estabelecimento das raízes da cana foram levantados os dados de temperatura do ar e graus -dia (TA e GD); temperatura do solo; umidade do ar e do solo.

Os dados de temperatura média diária do ar $\left({ }^{\circ} \mathrm{C}\right)$ foram fornecidos pelo posto meteorológico da fazenda. Para analisar os efeitos da temperatura do ar trabalhouse com a temperatura acumulada em graus-dia nas datas de amostragem. A equação utilizada para o cálculo de graus-dia (Maniero, 1980) foi a seguinte:

$$
\mathrm{GD}\left({ }^{\circ} \mathrm{C} \mathrm{dia}^{-1}\right)=[((\mathrm{TM}-\mathrm{Tm}) / 2)-\mathrm{TB}] . \mathrm{ND}
$$

$\mathrm{TM}=$ temperatura máxima

$\mathrm{Tm}=$ temperatura mínima

TB $=$ temperatura base $\left(20^{\circ} \mathrm{C}\right)$

$\mathrm{ND}=$ número de dias

Os dados de temperatura média do solo, em graus Celsius, foram obtidos a partir de medidas pela manhã e à tarde, através de termômetros colocados a $5 \mathrm{~cm}$ (TS 5) e $20 \mathrm{~cm}$ (TS 20) de profundidade, com uma regularidade, em média, de 15 dias.

A umidade relativa do ar foi obtida por higrômetro na estação meteorológica da fazenda.

A umidade do solo, em termos percentuais, foi avaliada nas profundidades de $0 \mathrm{~cm}$ a $20 \mathrm{~cm}$ (US(0-20) e de $20 \mathrm{~cm}$ a $40 \mathrm{~cm}$ (US(20-40)), através da diferença de massa entre solo úmido e seco, com uma regularidade, em média, de 15 dias.

O teste $F$ (ao nível de 1 e $5 \%$ de significância) foi utilizado para comparar todos os dados de índices biométricos entre cana crua e cana queimada.

Os dados de matéria seca de raízes foram correlacionados com os dados climatológicos, através da aplicação do teste de correlação de Pearson (Hoffmann, 1983).

\section{RESULTADOS}

Nos dois anos de amostragem as variações na matéria seca de raízes não apresentaram um padrão marcante de crescimento, embora não se tenham distinguido raízes vivas de raízes mortas (Figura 2).

A média da quantidade de raízes durante todo o ano de amostragem, comparando-se o $1^{\circ}$ e $2^{\circ}$ anos foi maior no $1^{\circ}$ ano tanto para cana crua como para cana queimada. As médias de matéria seca de raízes no $1^{\circ}$ ano foram: $0,2770 \mathrm{~g} \mathrm{~m}^{-3}$ para cana crua e $0,2713 \mathrm{~g} \mathrm{~m}^{-3}$ para cana queimada. No $2^{\circ}$ ano, as médias foram: 0,1981 e $0,2246 \mathrm{~g} \mathrm{~m}^{-3}$, respectivamente, para cana crua e cana queimada.

As diferenças significativas entre as médias dos tratamentos ocorreram apenas no $2^{\circ}$ ano, aos 68,167 e 344 DAC e a cana queimada foi o tratamento que mostrouse com valores maiores nas três datas (TABELA 1).

As correlações obtidas através da análise estatística para as datas, onde houve diferenças significativas, são apresentadas no TABELA 2.
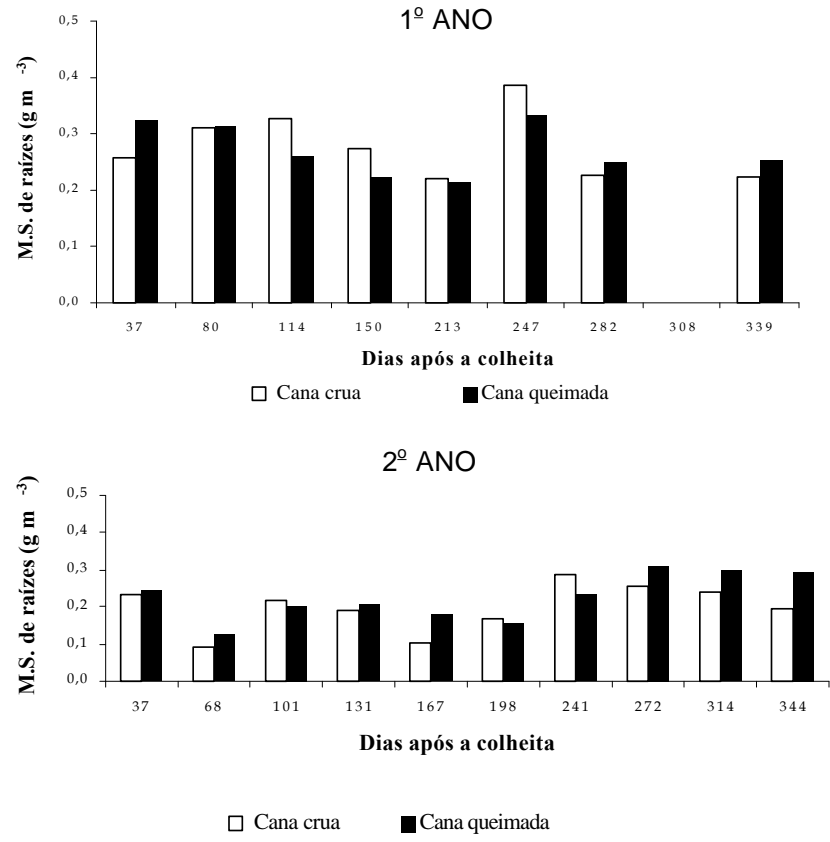

Figura 2 - Matéria seca de raízes $\left(\mathrm{g} \mathrm{m}^{-3}\right)$ no $1^{\circ}$ e $2^{\circ}$ ano de amostragem.

TABELA 1 - Média dos tratamentos para matéria seca de raízes, aos 68,167 e 344 DAC, no $2^{\circ}$ ano de amostragem.

\begin{tabular}{lcrrr}
\hline & \multicolumn{4}{c}{ DIAS APÓS A COLHEITA (DAC) } \\
\hline TRATAMENTO & 68 & 167 & 344 \\
Cana crua & 0,0939 A & 0,1032 B & 0,1936 B \\
Cana queimada & 0,1247 B & 0,1776 A & 0,2916 A \\
\hline F & $27,76 * *$ & $7,31^{*}$ & $6,85^{*}$ \\
\hline C.V. & 7,55 & 27,71 & 21,82 \\
\hline
\end{tabular}

* Nível de significância a $5 \%$.

** Nível de significância a $1 \%$.

TABELA 2 - Correlações da matéria seca de raízes com parâmetros climatológicos aos 68, 167 e 344 DAC, no $2^{\circ}$ ano de amostragem.

\begin{tabular}{|c|c|c|c|c|}
\hline 68 DIAS & \multicolumn{4}{|c|}{ PARÂMETROS CLIMATOLÓGICOS } \\
\hline TRATAMENTO & TS 5 & TS 20 & US $0-20$ & US $20-4 C$ \\
\hline Cana crua & $-0,2137$ & 02137 & 0,8837 & 0,8064 \\
\hline $\begin{array}{l}\text { Cana } \\
\text { queimada }\end{array}$ & $-0,2573$ & $-0,2573$ & $-0,7839$ & $-0,9460$ \\
\hline 167 DIAS & \multicolumn{4}{|c|}{ PARÂMETROS CLIMATOLÓGICOS } \\
\hline TRATAMENTO & TS 5 & TS 20 & US $0-20$ & US $20-40$ \\
\hline Cana crua & $-0,4979$ & $-0,4979$ & 0,8901 & 0,9387 \\
\hline $\begin{array}{l}\text { Cana } \\
\text { queimada }\end{array}$ & 0,1875 & 0,1875 & $-0,7362$ & 0,0090 \\
\hline 344 DIAS & \multicolumn{4}{|c|}{ PARÂMETROS CLIMATOLÓGICOS } \\
\hline TRATAMENTO & TS 5 & TS 20 & US $0-20$ & US $20-40$ \\
\hline ana crua & $-0,0509$ & 0,0509 & $0,9905^{*}$ & 0,9047 \\
\hline $\begin{array}{l}\text { Cana } \\
\text { queimada }\end{array}$ & 0,1260 & $-0,1260$ & 0,4113 & 0,5144 \\
\hline
\end{tabular}

* Nível de significância a 5\%. 
A maior porcentagem de raízes presentes no solo encontra-se nas camadas mais superficiais, para os dois anos de amostragem. No $1^{\circ}$ ano não houve diferença significativa entre a quantidade de matéria seca de raízes em $\mathrm{g} \mathrm{m}^{-3}$ de cana crua e a de cana queimada nas 5 profundidades avaliadas, assim como para a quantidade de raízes em termos de porcentagem. No $2^{\circ}$ ano, somente encontrou-se diferenças significativas no perfil $60-80 \mathrm{~cm}$, em termos de $\mathrm{g} \mathrm{m}^{-3}$ e porcentagem, com valores maiores para cana queimada. As TABELAS 3 e 4 mostram esses valores.

Para melhor entendimento de como se distribui o sistema radicular no perfil de solo mais próximo da canade-açúcar, as Figuras 3 e 4 representam a quantidade proporcional de raízes nos perfis em relação ao quadrante com o máximo de raiz encontrado, considerado como $100 \%$, no $1^{\circ}$ e $2^{\circ}$ ano de amostragem. A escala de cores representa a quantidade de raízes em cada quadrante e as letras e os números, utilizados para indicar o quadrante, conforme apresentado nas Figuras 3 e 4 . As cores são utilizadas a partir do quadrante, onde houve maior presença de raiz.
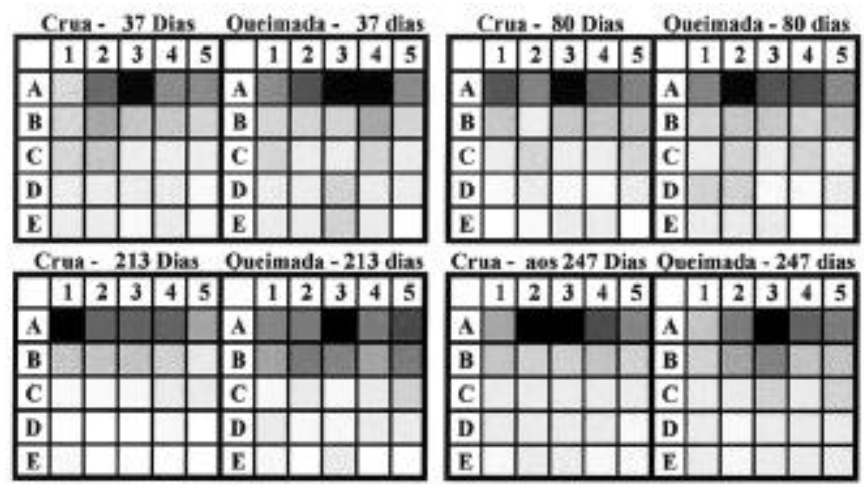

Figura 3 - Perfil de raízes no $1^{\circ}$ ano de amostragem.
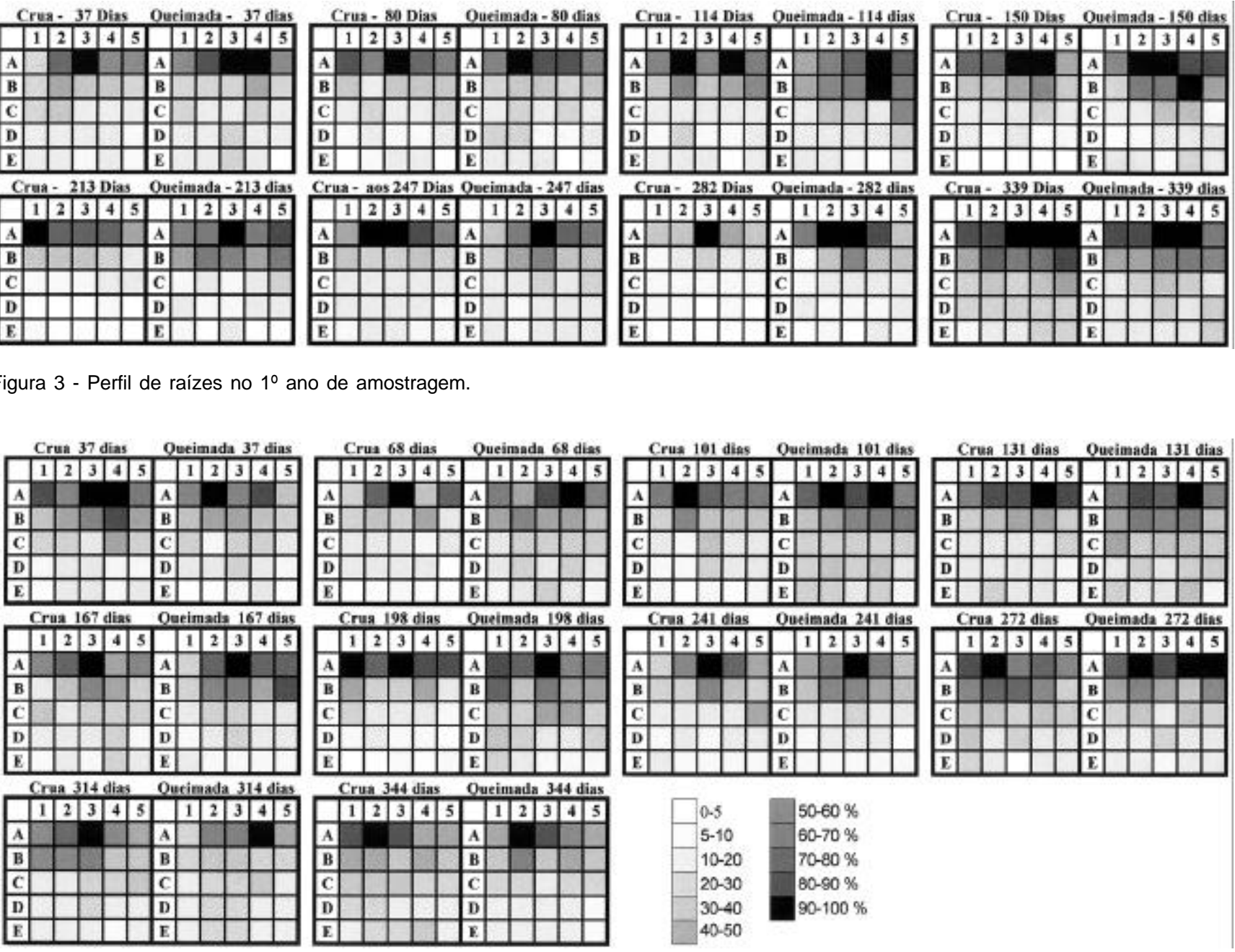

A matéria seca de raízes de cana queimada foi significativamente maior que a de cana crua, somente no $2^{\circ}$ ano, aos 68, 167 e 344 DAC (TABELA 1) e as quantidades de raízes foram maiores no $1^{\circ}$ ano que no $2^{\circ}$ ano, tanto para cana crua como para cana queimada (Figura 2).

O perfil do sistema radicular (Figuras 3 e 4) demonstrou que as raízes se concentraram mais na superfície e de forma mais marcante na proximidade do eixo da touceira, o que está de acordo com a literatura (Inforzato \& Alvarez, 1957; Sampaio et al., 1987; BallCoelho et al., 1992).

As profundidades são as seguintes: $A-0-20 \mathrm{~cm}$; B - 20-40 cm; C - 40-60 cm; D - 60-80 cm e E $80-100 \mathrm{~cm}$.

As distâncias do eixo principal da touceira são: 1 - 20-40 cm à esquerda; $2-0-20 \mathrm{~cm}$ à esquerda; 3 - eixo da touceira $(20 \mathrm{~cm}) ; 4-0-20 \mathrm{~cm}$ à direita e $5-20-40 \mathrm{~cm}$ à direita.

\section{DISCUSSÃO}
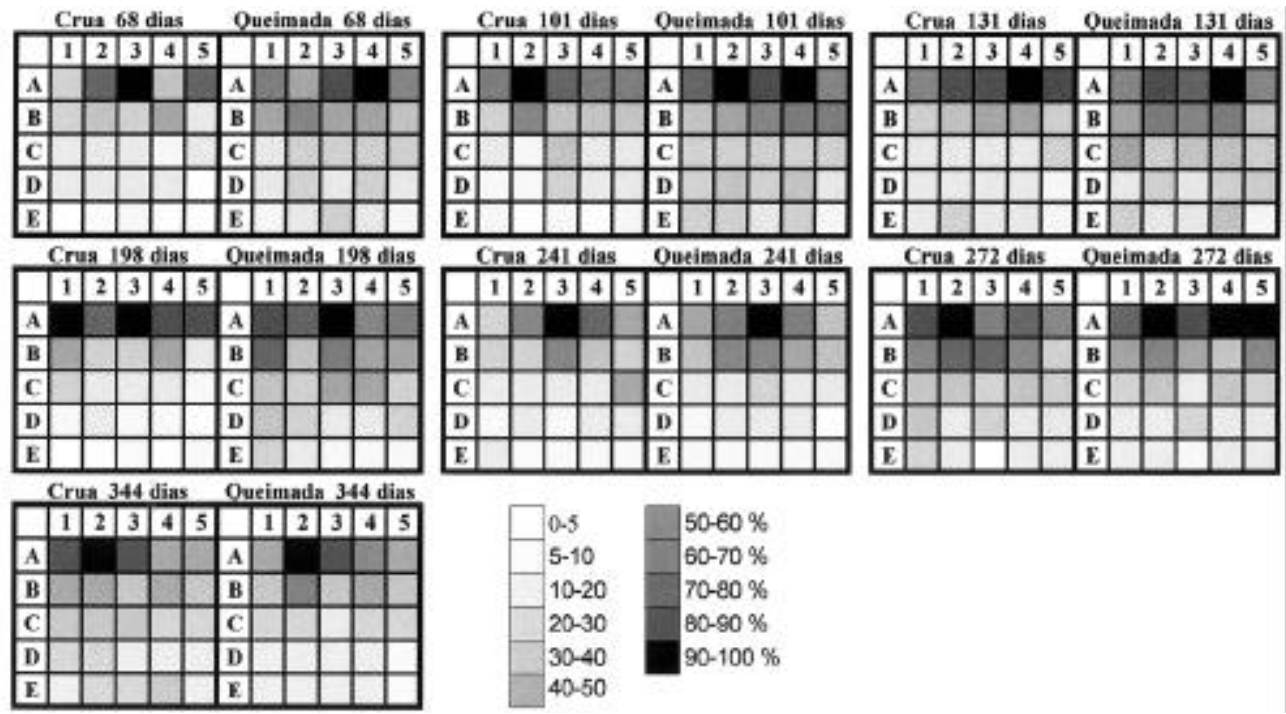

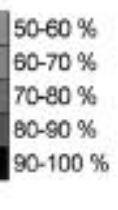

$50-60 \%$

$70-80 \%$

$30-50 \%$

$0-100 \%$

Figura 4 - Perfil de raízes no $2^{\circ}$ ano de amostragem. 
As raízes de cana crua distribuíram-se mais superficialmente no $1^{\circ}$ ano, com $75 \%$ nos primeiros 40 $\mathrm{cm}$, do que no $2^{\circ}$ ano, com $70 \%$. Em cana queimada a porcentagem de raízes até $40 \mathrm{~cm}$ foi de $72 \%$, no $1^{\circ}$ ano e no $2^{\circ}$ ano de $68 \%$ (TABELAS 3 e 4). Inforzato \& Alvarez (1957) encontraram $59 \%$ das raízes nos $30 \mathrm{~cm}$ iniciais de profundidade do solo; em Sampaio et al. (1987), $75 \%$ das raízes encontraram-se até $20 \mathrm{~cm}$ e; Ball-Coelho et al. (1992) observaram que $62,69 \%$ do sistema radicular distribuía-se nos $50 \mathrm{~cm}$.

A comparação estatística dos dados médios de matéria seca de raízes do $1^{\circ}$ ano de amostragem, distribuídos nas camadas do solo, não mostrou diferenças significativas entre cana crua e cana queimada em todas profundidades, em termos de $\mathrm{g} \mathrm{m}^{-3} \mathrm{e}$, em porcentagem de raízes (TABELA 3). № $2^{\circ}$ ano, houve diferenças relevantes na profundidade de $60-80 \mathrm{~cm}$, com dados maiores para cana queimada, em porcentagem e em $\mathrm{g} \mathrm{m}^{-3}$. Essa análise demonstra que, quando se compara cana crua e cana queimada, no $1^{\circ}$ ano não se pode afirmar que a porcentagem de raízes de cana queimada na superfície seja significativamente maior que a porcentagem de raízes de cana crua na superfície. No $2^{\circ}$ ano, ocorre o mesmo, ou seja, as raízes de cana crua não estão em maior concentração na superfície que as de cana queimada, do ponto de vista da análise estatística.

Por outro lado, a comparação entre a quantidade de raízes de cana crua e cana queimada, nas 5 profundidades, evidenciou que nas camadas mais profundas as raízes não aparecem com diferenças entre os tratamentos no $1^{\circ}$ ano, enquanto que no $2^{\circ}$ ano, a cana

TABELA 3 - Comparação entre as média dos tratamentos para matéria seca de raízes em porcentagem, em 5 profundidades de solo, no $1^{\text {ㅇ }}$ ano de amostragem.

\begin{tabular}{|c|c|c|c|c|}
\hline \multicolumn{5}{|c|}{ TRATAMENTOS } \\
\hline PROFUNDIDADE & Cana crua & $\begin{array}{c}\text { Cana } \\
\text { queimada }\end{array}$ & $\mathrm{F}$ & $\mathrm{CV}$ \\
\hline -------- cm ------- & 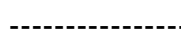 & - $\mathrm{g} \mathrm{m}^{-3}$------. & ------- & $\%$ \\
\hline $0-20$ & $0,1254 \mathrm{~A}$ & $0,1114 \mathrm{~A}$ & 1,18 & 15,43 \\
\hline $20-40$ & $0,0604 \mathrm{~A}$ & $0,0628 \mathrm{~A}$ & 0,31 & 9,96 \\
\hline $40-60$ & $0,0276 \mathrm{~A}$ & $0,0288 \mathrm{~A}$ & 0,06 & 24,55 \\
\hline $60-80$ & $0,0188 \mathrm{~A}$ & $0,0207 \mathrm{~A}$ & 0,57 & 18,32 \\
\hline $80-100$ & $0,0141 \mathrm{~A}$ & $0,0176 \mathrm{~A}$ & 5,61 & 13,29 \\
\hline \multicolumn{5}{|c|}{ TRATAMENTOS } \\
\hline PROFUNDIDADE & Cana crua & $\begin{array}{c}\text { Cana } \\
\text { queimada }\end{array}$ & $\mathrm{F}$ & CV \\
\hline $0-20$ & $50,90 \mathrm{~A}$ & $46,00 \mathrm{~A}$ & 1,21 & 12,99 \\
\hline $20-40$ & $24,52 \mathrm{~A}$ & $26,03 \mathrm{~A}$ & 0,71 & 10,03 \\
\hline $40-60$ & $11,19 \mathrm{~A}$ & $12,01 \mathrm{~A}$ & 0,14 & 26,20 \\
\hline $60-80$ & $7,65 \mathrm{~A}$ & $8,64 \mathrm{~A}$ & 0,66 & 21,22 \\
\hline $80-100$ & $5,73 \mathrm{~A}$ & $7,32 \mathrm{~A}$ & 5,15 & 15,09 \\
\hline
\end{tabular}

crua não sobressaiu-se em relação à cana queimada, até mesmo apresentando quantidades menores de raízes dos 60-80 cm de profundidade. De maneira geral, na cana crua há um maior acúmulo de raízes em superfície e na queimada em profundidade devido à maior umidade no solo com palha.

Portanto, quando se considera a média de todas as datas de coleta dos dados em cada ciclo de crescimento, nos dois anos de amostragem, por camada de profundidade do solo, pode-se afirmar que a influência da palha na cana crua não foi um fator que causasse diferenças no crescimento de raízes em cana crua.

A análise comparativa dos dados climatológicos mostrou que a curva de temperatura do solo de cana crua (Figura 6) mostrou um comportamento diferente do de cana queimada, tendo uma queda aos 68 DAC. A curva de acúmulo de graus-dia apresenta uma estabilização nesse período (Figura 5), coincidindo com um acúmulo maior da matéria seca de raízes de cana crua.

Aos 167 DAC ( $2^{\circ}$ ano), a ocorrência de diferença entre o desenvolvimento de raízes de cana crua e cana queimada é de difícil análise, em termos de influência de parâmetros climatológicos, uma vez que não há correlações. Recorrendo-se aos gráficos comparativos, observa-se que os de temperatura do solo (Figura 6 e 7) não demonstram uma grande diferença entre os dois tratamentos, para as 2 profundidades. Nessa data, a temperatura do solo $(5 \mathrm{~cm})$ apresentou seu pico máximo, não havendo uma mudança de tendência, em relação às datas anteriores, para as duas profundidades.

TABELA 4 - Comparação entre as médias dos tratamentos para matéria seca de raízes e em porcentagem, em 5 profundidades de solo, no $2^{\circ}$ ano de amostragem.

\begin{tabular}{|c|c|c|c|c|}
\hline \multicolumn{5}{|c|}{ TRATAMENTOS } \\
\hline PROFUNDIDADE & Cana crua & $\begin{array}{c}\text { Cana } \\
\text { queimada }\end{array}$ & $\mathrm{F}$ & CV \\
\hline ------cm ------ & --o-- & $--g^{-3}-\cdots-$ & --- & $\%$ \\
\hline $0-20$ & $0,0898 \mathrm{~A}$ & $0,0940 \mathrm{~A}$ & 0,21 & 14,13 \\
\hline $20-40$ & $0,0509 \mathrm{~A}$ & $0,0277 \mathrm{~A}$ & 2,47 & 13,34 \\
\hline $40-60$ & $0,0314 \mathrm{~A}$ & $0,0326 \mathrm{~A}$ & 2,18 & 12,02 \\
\hline $60-80$ & $0,0177 \mathrm{~B}$ & 0,0227 A 2 & $24,92^{* *}$ & 7,06 \\
\hline $80-100$ & $0,0136 \mathrm{~A}$ & $0,0172 \mathrm{~A}$ & 3,91 & 16,59 \\
\hline \multicolumn{5}{|c|}{ TRATAMENTOS } \\
\hline PROFUNDIDADE & Cana crua & $\begin{array}{c}\text { Cana } \\
\text { queimada }\end{array}$ & $\mathrm{F}$ & CV \\
\hline $0-20$ & $44,84 \mathrm{~A}$ & $41,92 \mathrm{~A}$ & 2,43 & 6,11 \\
\hline $20-40$ & $25,60 \mathrm{~A}$ & $26,24 \mathrm{~A}$ & 0,20 & 7,79 \\
\hline $40-60$ & $13,81 \mathrm{~A}$ & $14,01 \mathrm{~A}$ & 0,18 & 4,94 \\
\hline $60-80$ & 8,88 B & $10,16 \mathrm{~A}$ & $9,28^{*}$ & 6,20 \\
\hline $80-100$ & $6,87 \mathrm{~A}$ & $7,66 \mathrm{~A}$ & 1,11 & 14,67 \\
\hline
\end{tabular}

* Nível de significância a $5 \%$.

** Nível de significância a $1 \%$. 

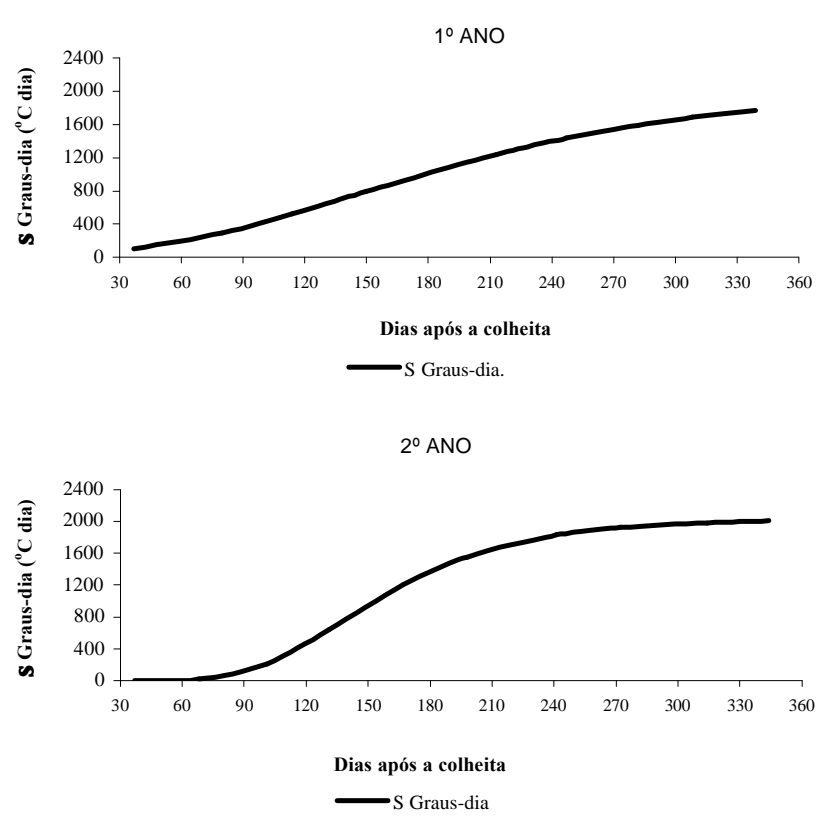

Figura 5 - Acúmulo de Graus dia (ํㅡ dia) no $1^{\circ}$ e $2^{\circ} \stackrel{\circ}{\text { ano }}$ de amostragem.

$1^{0}$ ANO-Cana crua
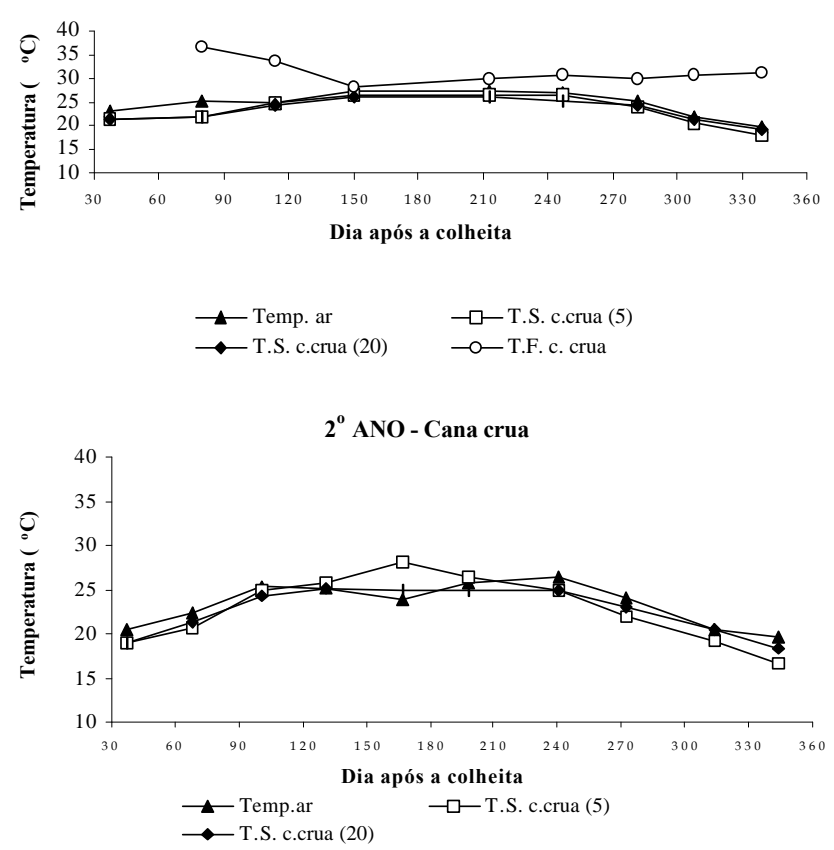

Figura 6 - Comparação entre temperatura do ar, da folha e do solo para cana crua no $1^{\circ}$ e $2^{\circ}$ ano de amostragem.

Aos 344 DAC, a cana queimada não se correlaciona com nenhum parâmetro, somente a cana crua, com um índice positivo de 0,9905 com a umidade do solo a 0-20 cm.

A distribuição lateral do sistema radicular é mais marcante na proximidade do eixo da touceira, mas não é tão clara quanto a distribuição das raízes nas primeiras profundidades.
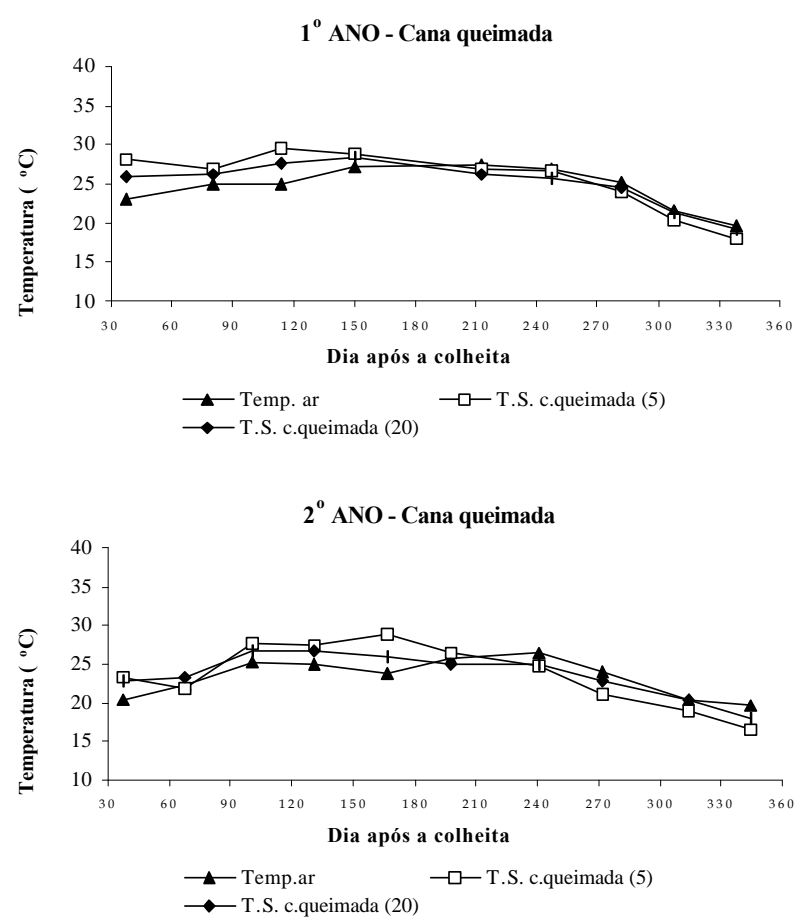

Figura 7 - Comparação entre temperatura do ar, da folha e do solo para cana queimada no $1^{\circ}$ e $2^{\circ}$ ano de amostragem.

A análise dos perfis nos DAC de diferenças significativas, mostra que, aos 68 DAC do $2^{\circ}$ ano (Figura 4), as raízes de cana queimada já atingiam camadas mais profundas em uma concentração maior que as da cana crua e, de uma maneira geral, nas outras datas as raízes de cana queimada apresentam-se com melhor distribuição que as da cana crua. As umidades do solo de cana crua são praticamente semelhantes as de cana queimada, o que leva a supor que a concentração mais elevada de umidade na superfície não estimula a raiz a crescer até camadas mais profundas. Por isso, talvez, a capacidade de crescer em camadas mais profundas, deve estar relacionada com a disponibilidade hídrica, o que pode ter contribuído para que os valores maiores de raízes na cana queimada, no $2^{\circ}$ ano. Inforzato \& Alvarez (1957) e Camargo (1968) relataram esse fato acima exposto, de que a distribuição das raízes no solo é muito afetada pela umidade do mesmo.

Todavia, aos 167 e 344 DAC, a cana crua não apresenta uma distribuição radicular tão distinta da cana queimada como aos $68 \mathrm{DAC}$, embora esta última tenha raízes espalhadas em todo perfil.

A umidade do solo, mesmo apresentando correlação significativa $(0,995)$ com a matéria seca de raízes de cana crua aos 344 DAC, não está mais influenciando o sistema radicular da cana crua a distribuirse superficialmente da mesma forma aos 68 DAC, como demonstra a Figura 8, onde não se observa uma diferença tão grande entre a umidade do solo de cana crua e de cana queimada, aos 344 DAC. 

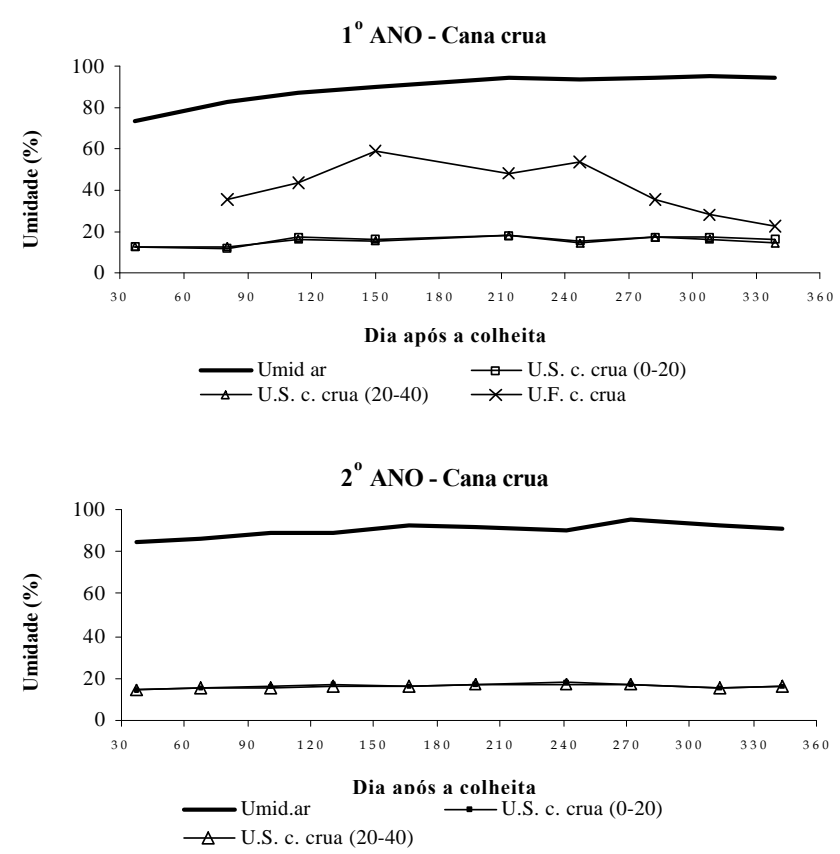

Figura 8 - Comparação entre umidade do ar, da folha e do solo para cana crua no $1^{\circ}$ e $2 \stackrel{0}{\text { ano amostragem. }}$

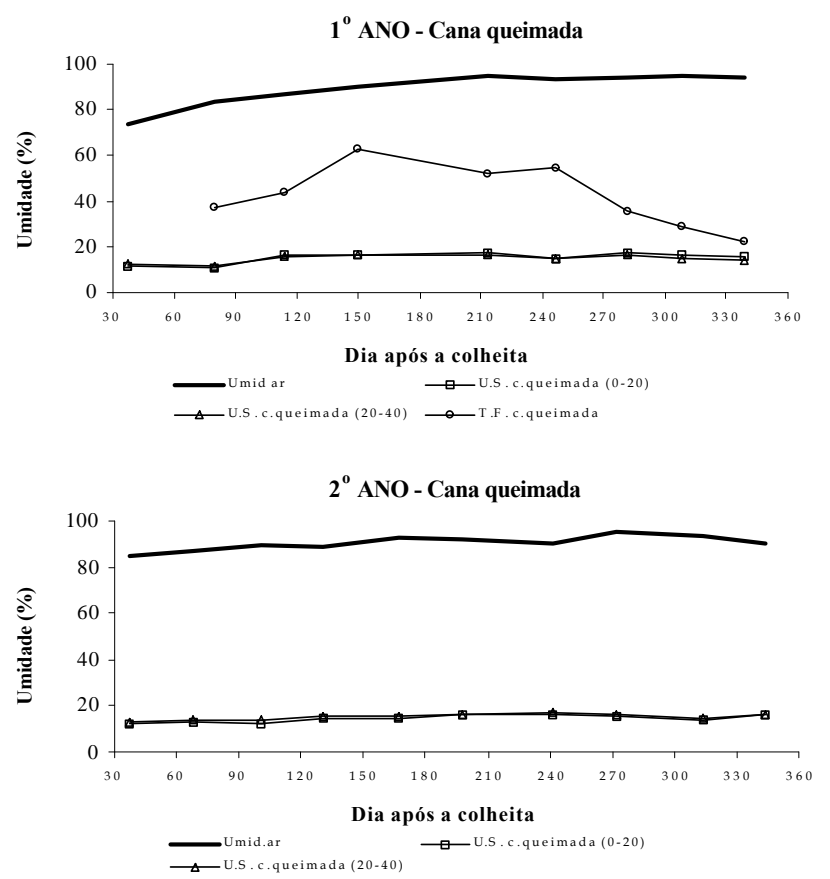

Figura 9 - Comparação entre umidade do ar, da folha e do solo para cana queimada no $1^{\circ}$ e $2^{\circ}$ ano de amostragem.

\section{CONCLUSÕES}

As diferenças expressas do primeiro para o segundo ano são devidas aos fatores climatológicos, tanto para cana crua como cana queimada, apesar de, isoladamente, não provocarem diferenças na comparação entre os dois tratamentos.
No primeiro ano de determinação a distribuição quantitativa do sistema radicular (matéria seca) mostrou-se superior na cana crua (colheita mecanizada) em relação à cana queimada (colheita manual), enquanto que, no segundo ano, o resultado foi inverso.

Nas camadas de solo exploradas, não se observaram diferenças significativas na distribuição de raízes da cana crua, comparando-se à cana queimada, com exceção do nível $60-80 \mathrm{~cm}$ no segundo ano.

\section{REFERÊNCIAS BIBLIOGRÁFICAS}

BALL-COELHO, B.; SAMPAIO, E.V.S.B.; TIESSEN, H.; STEWART, J.W.B. Root dynamic in plant ratoon crops of sugar cane. Plant and Soil, v.142, p.297-305, 1992.

BLACKBURN, F. Sugarcane. New York: Longman, 1984. 414p. CAMARGO, P.N. Fisiologia da cana-de-açúcar. Piracicaba: ESALQ, 1968. 38p.

CASAGRANDE, A.A. Tópicos de morfologia e fisiologia da cana-de-açúcar. Jaboticabal: FUNEP, 1991. 157p.

FERNANDES, J. A subsolagem no controle da compactação do solo na cana-soca (Saccharum sp.) variedade CB 41-76 e seus efeitos no rendimento agrícola e no sistema radicular. Piracicaba, 1979. Dissertação (Mestrado) - Escola Superior de Agricultura "Luiz de Queiroz", Universidade de São Paulo.

HOFFMANN, R.; VIEIRA, F. Análise de regressão: uma introdução à econometria. São Paulo: HUCITEC, 1983.

INFORZATO, R.; ALVAREZ, R. Distribuição do sistema radicular da cana-de-açúcar va. 290 , em solo tipo terra-roxa legítima. Bragantia, v.16, p.1-13, 1957.

KOPKE, V. Methods for studying root growth. In: SYMPOSIUM ON THE SOIL/ROOT SYSTEM IN RELATION TO BRAZIL AGRICULTURE, Londrina, 1980. Proceedings. Londrina: Fundação Instituto Agronômico do Paraná, 1981. p.130.

KORNDORFER, G.H. PRIMAVESI, O.; DEUBER, R. Crescimento e distribuição do sistema radicular de canade-açúcar em solo LVA. Piracicaba: Coopersucar, 1989. 82p. (Boletim Técnico, 47)

MACHADO, E.C. Fisiologia de produção de cana-de-açúcar In: PARANHOS, S.B. (Coord.) Cana-de-açúcar: cultivo e utilização. Campinas: Fundação Cargill, 1987. v.1, cap.1, p.56-87.

MANIERO, M.A. Aplicação do método de graus dia em canade-açúcar (Saccharum spp.) Piracicaba, 1980. 76p. Dissertação (Mestrado) - Escola Superior de Agricultura "Luiz de Queiroz", Universidade de São Paulo.

SAMPAIO, E.V.S.B.; SALCEDO, J.H.; CAVALCANTI, F.J.A. Dinâmica de nutrientes em cana-de-açúcar: III. Conteúdo de nutrientes e distribuição do sistema radicular no solo. Pesquisa Agropecuária Brasileira, v.22, p.425-431, 1987.

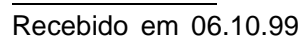

